\title{
Peningkatan Belajar Mandiri Siswa di Sekolah Melalui Layanan Informasi Dengan Media Sinematografi
}

\author{
Febriansyah \\ Institut Agama Islam Negeri (IAIN) Curup \\ Febri0402ansyah@gmail.com
}

\begin{abstract}
The research objective was to reveal whether there were differences in students' independent learning before (pre-test) and after (posttest) providing information services with cinematographic media. It was found that the phenomenon of student independent learning was low, the desire of students was less to learn, and the lack of understanding of students in learning. One type of guidance and counseling service that can be used to improve students' independent learning in schools is information services using cinematographic media. This research is a quantitative research with a Quasi Experiment model with One Group Pretest-Posttest Design. The population was students with a total of 99 students and a sample of 32 people who were determined purposively. How to collect data through self-learning scale. Data were analyzed using Paired Sample's T-Test with the help of SPSS version 20.00. The findings of the study show that information services using cinematographic media are effective for improving students 'independent learning in schools and there are differences in students' independent learning in schools in the pre-test and posttest after treatment using information services with cinematographic media. This research can be concluded that the independent learning of students in schools can be improved through information services with cinematographic media. This study shows that the importance of implementing information services with cinematographic media in schools by school counselors so as to improve students' independent learning in schools.
\end{abstract}

Keywords: Service information, independent learning, media cinematographic 


\begin{abstract}
Abstrak
Tujuan penelitian adalah untuk mengungkap apakah ada terdapat perbedaan belajar mandiri siswa sebelum (pre-test) dan sesudah (post-test) pemberian layanan informasi dengan media sinematografi. Ditemukan fenomena belajar mandiri siswa yang rendah, keinginan siswa kurang untuk belajar, kurangnya pemahaman siswa dalam belajar. Salah satu jenis layanan bimbingan dan konseling yang bisa digunakan untuk meningkatkan belajar mandiri siswa di sekolah adalah layanan informasi dengan media sinematografi. Penelitian ini adalah penelitian kuantitatif dengan model Quasi Eksperimen dengan One Group Pretest-Posttest Design. Populasi adalah siswa dengan jumlah siswa 99 orang dan sampel sebanyak 32 orang yang ditentukan secara purposive. Cara pengumpulan data melalui skala belajar mandiri. Data dianalisis dengan menggunakan paired sampel T-Test dengan bantuan SPSS versi 20.00. Temuan penelitian menunjukkan bahwa layanan informasi dengan media sinematografi efektif untuk meningkatkan belajar mandiri siswa di sekolah dan terdapat perbedaan belajar mandiri siswa di sekolah pada pre-test dan post-test setelah pemberian perlakuan menggunakan layanan informasi dengan media sinematografi. Penelitian ini dapat disimpulkan bahwa belajar mandiri siswa di sekolah dapat ditingkatkan melalui layanan informasi dengan media sinematografi. Penelitian ini menunjukkan bahwa pentingnya melaksanakan layanan informasi dengan media sinematografi di sekolah oleh konselor sekolah sehingga dapat meningkatkan belajar mandiri siswa di sekolah.
\end{abstract}

Kata Kunci: Layanan informasi, belajar mandiri, media sinematografi

\title{
Pendahuluan
}

Dalam kehidupan sehari-hari siswa sering kali meremehkan yang namanya belajar, banyak para siswa menganggap belajar itu tidaklah penting hanya membuang-buang waktu lebih baik menghabiskan waktu untuk berkumpul dengan teman sebaya. Para siswa masih banyak belum mengetahui pentingnya belajar, sesungguhnya belajar itu adalah tugas utama siswa. Belajar akan bermakna bila siswa berperan aktif dalam proses belajar dan mampu memutuskan apa yang harus diperbaiki. Dalam belajar itu ada belajar mandiri, di mana belajar mandiri merupakan kegiatan belajar aktif yang didorong oleh niat atau motif untuk menguasai suatu kompetensi guna untuk menyelesaikan suatu 
masalah, hal tersebut dibangun dengan bekal pengetahuan atau kompetensi yang telah dimiliki. ${ }^{1}$

Kegiatan belajar mandiri dapat diawali dengan kesadaran akan pentingnya belajar. Dengan adanya kesadaran tersebut, pada dalam diri individu akan muncul ketertarikan atau minat dan motivasi untuk belajar, ${ }^{2}$ baik belajar dalam konteks pembelajaran di kelas maupun dalam belajar mandiri atau tanpa bantuan orang lain. Secara kelembagaan, bimbingan dan konseling (selanjutnya disingkat BK) adalah bagian dari keseluruhan program pendidikan di sekolah. Guru BK/Konselor sekolah adalah guru yang ditugaskan untuk melaksanakan kegiatan BK di sekolah. Guru BK bertanggung jawab untuk merencanakan dan menindak lanjuti pelayanan BK terhadap peserta didik yang menjadi tanggung jawabnya. ${ }^{3}$

Salah satu layanan BK yang dapat diterapkan untuk mengatasi permasalahan belajar mandiri siswa di sekolah adalah melalui layanan informasi. Winkel menambahkan layanan informasi berusaha memenuhi kekurangan informasi yang diperlukan. ${ }^{4}$ Berkenaan dengan hal ini, layanan informasi dapat menjadi salah satu alternatif dalam peningkatan belajar mandiri siswa. Pemberian layanan informasi yang diberikan sebagai upaya untuk meningkatkan belajar mandiri siswa dapat dilakukan dengan memanfaatkan media sinematografi. Sesuai dengan pendapat Hamdani bahwa media sinematografi adalah merupakan media perantara atau penggunaan materi dan penerapannya melalui pandangan dan pendengaran sehingga membangun kondisi yang dapat membuat siswa mampu memperoleh pengetahuan, keterampilan, atau sikap. ${ }^{5}$ Peneliti mencoba memberikan alternatif sebagai upaya membantu siswa mengatasi belajar mandiri yang rendah di sekolah yaitu dengan memanfaatkan layanan informasi dengan media, seperti dalam beberapa penelitian sebelumnya, banyak yang menyebutkan bahwa media merupakan salah satu alat perantara yang sangat efisien dalam memberikan materi pembelajaran, Sutrisno menyampaikan bahwa motivasi belajar siswa mengalami peningkatan setelah menggunakan media (Media videoklip). ${ }^{6}$

Penelitian ini berangkat dari fenomena belajar mandiri siswa yang rendah, keinginan siswa kurang untuk belajar, kurangnya pemahaman siswa

${ }^{1}$ Mudjiman, H. 2007. Belajar Mandiri. Yogyakarta : UNY Press.

${ }^{2}$ Sutarto, S., Sari, D. P., \& Fathurrochman, I. (2020). Teacher strategies in online Learning To Increase Students' Interest in Learning During Covid-19 pandemic. Jurnal Konseling dan Pendidikan, 8(3).

${ }^{3}$ Prayitno \& Amti. 1999. Dasar-dasar Bimbingan dan Konseling. Jakarta: Rineka Cipta.

${ }^{4}$ Winkel, W. S. 1997. Bimbingan dan Konseling di Institusi Pendidikan. Jakarta: Gramedia Widiasarana

${ }^{5}$ Hamdani, 2011. Strategi Belajar Mengajar. Bandung: CV Pustaka Setia

6 Sutrisno, (2020), Meningkatkan Motivasi Belajar Siswa Melalui Layanan Bimbingan Kelompok Dengan Media Video-klip. Vol. 3 No. 1, Februari 2020 Hal. 22-27 
dalam belajar, dimana tujuan penelitian adalah untuk mengungkap apakah ada terdapat perbedaan belajar mandiri siswa sebelum (pre-test) dan sesudah (posttest) pemberian layanan informasi. Penelitian ini menggunakan pendekatan kuantitatif yang pengolahan datanya dilakukan dengan metode statistik. Metode kuantitatif ditujukan untuk mengetahui perubahan antara sebelum dilakukan tindakan (treatment) dan setelah dilakukan tindakan. Desain yang digunakan dalam penelitian ini adalah penelitian eksperimen. Pelaksanaan quasi experiment dengan One Group Pretest-Posttest Design, dilakukan sebanyak 8 (delapan) sesi, yang dilakukan selama 6 (enam) kali pertemuan. Teknik pengambilan subjek yang digunakan dalam penelitian ini adalah teknik non random sampling, yaitu dengan metode sampling purposive sebanyak 32 orang siswa dari populasi siswa yang berjumlah 99 orang. Teknik analisis data yang digunakan adalah dengan menggunakan uji t atau $t$ test.

\section{Hasil dan Pembahasan}

Pemberian pretest bertujuan untuk mengetahui gambaran awal kondisi belajar mandiri siswa sebelum diberikan perlakuan. Adapun hasil pretest yang diperoleh dapat dilihat pada tabel 1 berikut.

\section{Tabel 1 : Distribusi Nilai Rata-rata Pada Tahap Pretest.}

\begin{tabular}{|l|l|l|}
\hline Sampel & \multirow{2}{*}{ Rata-rata } \\
\hline Tahap & N & \\
\hline Pretest & 32 & 96,03125 \\
\hline
\end{tabular}

Dari table 1, dapat dilihat bahwa rata-rata skor pretest belajar mandiri siswa sebesar 96,03125. Pemberian perlakuan sebanyak 8 (delapan) sesi kepada kelompok penelitian selama 6 (enam) minggu, kemudian peneliti mengukur tingkat belajar mandiri siswa. Hasil setelah diberikannya perlakuan (posttest) bisa dilihat pada tabel 2 berikut ini.

Tabel 2 : Distribusi Nilai Rata-rata Pada Tahap Posttest.

\begin{tabular}{|l|l|l|}
\hline Sampel & \multirow{2}{*}{ Rata-rata } \\
\hline Tahap & $\mathrm{N}$ & \\
\hline Posttest & 32 & 109.156 \\
\hline
\end{tabular}

Dari table 2, dapat dilihat bahwa rata-rata pada tahap posttest sebesar 109.156. Dari hasil analisis dapat disimpulkan bahwa uji formalitas data belajar mandiri siswa ber distribusi normal dengan menggunakan Kolmogorov Smirnov. 
Pengujian hipotesis yang diajukan dalam penelitian ialah "Terdapat perbedaan belajar mandiri siswa sebelum (pre-test) dan sesudah (post-test) perlakuan menggunakan layanan informasi dengan media sinematografi“. Pengujian hipotesis ini dilakukan dengan uji $\mathrm{t}$ atau $\mathrm{t}$ tes menggunakan SPSS versi 20.00 Berdasarkan hal tersebut didapatkan hasil perhitungan seperti yang terangkum pada tabel berikut ini.

Tabel 3: Hasil analisis uji T Test Belajar Mandiri Siswa

\begin{tabular}{|l|l|l|l|l|l|l|}
\hline \multicolumn{2}{|c|}{} & $\begin{array}{l}\text { Mean } \\
\text { Difference }\end{array}$ & Std. Dev & $\mathrm{t}$ & $\mathrm{df}$ & $\begin{array}{l}\text { Sig. (2- } \\
\text { tailed) }\end{array}$ \\
\hline $\begin{array}{l}\text { Belajar } \\
\text { Mandiri }\end{array}$ & Pre-test & 64,03125 & 10,66946 & 33,949 & 31 &, 000 \\
\cline { 2 - 8 } & Post-test & 77,15625 & 12,79644 & 34,108 & 31 &, 000 \\
\hline
\end{tabular}

Dari tabel 3, terlihat bahwa angka probabilitas Asmyp. Sig.(2-tailed) belajar mandiri siswa sebesar 0,000 , atau probabilitas di bawah alpha $0,05(0,000$ $<0,05)$. dari hasil tersebut maka Ho ditolak dan HI diterima. Berdasarkan hasil pengujian hipotesis ialah terdapat perbedaan belajar mandiri sebelum (pretest) dan sesudah (posttest) menggunakan layanan informasi dengan media sinematografi. Pengujian hipotesis ini dilakukan dengan uji $\mathrm{t}$ atau $\mathrm{t}$ tes dan dari hasil analisis data terlihat bahwa angka probabilitas Asmyp. Sig.(2-tailed) belajar mandiri siswa sebesar 0,000 , atau probabilitas di bawah alpha $0,05(0,000<0,05)$ dari hasil tersebut maka Ho ditolak dan HI diterima. Dengan demikian hipotesis yang diuji dalam penelitian ini dapat diterima, yaitu "terdapat perbedaan yang signifikan antara belajar mandiri sebelum (pretest) dan sesudah (posttest) perlakuan menggunakan layanan informasi dengan media sinematografi”.

Berdasarkan data tersebut dapat diartikan belajar mandiri siswa meningkat setelah diberikan layanan informasi dengan media sinematografi, peningkatan ini diasumsikan karena dalam layanan informasi dengan media sinematografi yang memungkinkan siswa belajar berpartisipasi aktif dalam berbagai pengalaman untuk mencegah timbulnya masalah, memecahkan masalah, serta mengembangkan dan memelihara potensi yang ada. Ditambah lagi dengan media sinematografi sebagai perantara atau penggunaan materi dan penyerapan melalui pandangan dan pendengaran sehingga membangun kondisi yang dapat membuat siswa mampu memperoleh pengetahuan, keterampilan atau sikap. Hal ini sesuai dengan pendapat Prayitno bahwa layanan informasi bertujuan untuk membekali individu dengan berbagai pengetahuan dan pemahaman tentang berbagai hal yang berguna untuk mengenal diri, merencanakan dan mengembangkan pola kehidupan sebagai pelajar, anggota 
keluarga dan masyarakat. ${ }^{7}$ Menurut Ita Dwaita layanan informasi bisa menjadi salah satu perantara dalam meningkatkan motivasi belajar, dimana dalam penelitiannya Ita mencoba meningkatkan motivasi belajar siswa dengan cara memberikan layanan informasi dan hasil nya sungguh efisien dan bisa dikatakan bahwa layanan informasi sangat membantu para tenaga pendidik dalam melakukan proses pembelajaran. ${ }^{8}$

Purwoko menyampaikan penyajian informasi ialah kegiatan membantu siswa dalam mengenali lingkungannya, terutama tentang kesempatankesempatan yang ada di dalamnya, yang dapat dimanfaatkan dengan baik untuk masa kini maupun masa yang akan datang. ' Informasi yang dimaksudkan adalah memberikan wawasan kepada para siswa agar dapat menggunakan informasi secara baik untuk mencegah atau mengatasi kesulitan yang dihadapinya, serta untuk merencanakan masa depan. Uraian dari pembuktian hipotesis ini mengisyaratkan bahwa keberhasilan pelayanan konseling, khususnya layanan informasi, ditentukan oleh beberapa faktor diantaranya adalah penggunaan media sinematografi.

Pelayanan konseling melalui layanan informasi merupakan proses pembelajaran yang berlangsung dalam suatu sistem dimana media pembelajaran menempati posisi yang cukup penting dalam sistem pembelajaran. Sistem pembelajaran bahwa tanpa media, komunikasi tidak akan terjadi dan proses pembelajaran sebagai proses komunikasi juga tidak akan bisa berlangsung secara optimal. Media pembelajaran adalah komponen integral dari sistem pembelajaran. ${ }^{10}$ Oleh sebab itu, sebagai konselor yang professional dalam memberikan layanan informasi semestinya menggunakan media sinematografi, sehingga belajar mandiri siswa bisa meningkatkan ke arah yang lebih baik.

Dari paparan dan penjelasan di atas hendaknya layanan informasi dengan media sinematografi semestinya dapat meningkatkan belajar mandiri siswa ke arah yang lebih positif. Belajar mandiri dapat berlaku secara positif atau negatif tergantung dengan sikap dan pandangannya terhadap individu dan lingkungan khususnya dalam kehidupan di sekolah. Kesimpulan dari analisis data bahwa layanan informasi dengan media sinematografi sangat efektif dalam meningkatkan belajar mandiri siswa.

\footnotetext{
7 Prayitno. 2012. Jenis Layanan dan Kegiatan Pendukung Konseling (Pendidikan Profesi Konseling). FIP. UNP

8 Ita Dwaita Lantari, 2020, Upaya Meningkatkan Motivasi Belajar Siswa Melalui Layayan Informasi, Jurnal Education and Economics - Vol.03, No.01 (Januari-Maret) 2020

9 Purwoko, B. 2008. Organisasi dan Managemen Bimbingan Konseling. Surabaya: Unesa University Press

${ }^{10}$ Ridwan, B. 2013. Media Pembelajaran. STAIN Salatiga.
} 


\section{Penutup}

Berdasarkan hasil penelitian dan setelah melakukan analisis statistik dan uji hipotesis, dapat disimpulkan secara umum bahwa layanan informasi dengan media sinematografi dapat meningkatkan belajar mandiri siswa, khususnya adalah terdapat perbedaan signifikan antara belajar mandiri siswa sebelum (pretest) dan sesudah perlakuan (post-test) layanan informasi dengan media sinematografi. Berdasarkan hal tersebut layanan informasi dengan media sinematografi lebih dapat meningkatkan belajar mandiri siswa di sekolah. Layanan informasi yang bersifat dinamis memungkinkan berkembangnya keinginan, kemampuan dan semangat siswa untuk belajar sehingga membantu siswa untuk memperoleh hasil belajar yang maksimal. Pelaksanaan layanan informasi dengan media sinematografi dapat lebih diintensifkan dan diutamakan baik dalam bentuk orientasi dan sosialisasi maupun implementasi ke dalam bentuk program di sekolah. Oleh karena itu diperlukan peran serta yang aktif dari kepala sekolah, konselor sekolah dan orang tua siswa karena dengan perhatian kedua belah pihak akan mengajari siswa sebagai individu yang percaya diri dan matang.

Beberapa saran yang diajukan sebagai tindak lanjut penelitian ini anatara lain, bagi konselor sekolah agar meningkatkan keilmuan dalam bidang BK khususnya dalam pemberian layanan informasi dengan media sinematografi dan dapat menyelenggarakan layanan informasi dengan media sinematografi, dikarenakan hal ini efektif untuk meningkatkan belajar mandiri siswa. Kepalas sekolah, hendaknya dapat mengayomi para Konselor dalam meningkatkan pelayanan BK di sekolah dan mendorong siswa untuk memanfaatkan layanan BK secara sukarela dan berdasarkan kesadaran diri. Kepada siswa untuk optimalisasi layanan informasi dengan media sinematografi perlu partisipasi aktif siswa sehingga tercapai tujuan yang optimal dan peneliti lainnya hendakny hasil penelitian ini dapat dikembangkan melalui penelitian lanjutan berkenaan dengan masalah pengembangan belajar mandiri siswa.

\section{Bibliografi}

Ali, M \& Asrori. M. 2012. Psikologi Remaja. Perkembangan Peserta Didik. Jakarta: Bumi Aksara.

Arsyad, A. 2013. Media Pembelajaran. Jakarta: PT. Radja Grafindo Persada.

Brockett, R.G. \& Hiemstra, R. 1991. A conceptual framework for understanding selfdirection in adult learning In: Self-Direction in adult learning: perspectives on theory, research, and practice. London: Routledge.

Hamdani, 2011. Strategi Belajar Mengajar. Bandung: CV Pustaka Setia 
Ita Dwaita Lantari, 2020, Upaya Meningkatkan Motivasi Belajar Siswa Melalui Layayan Informasi, Jurnal Education and Economics - Vol.03, No.01 (Januari-Maret) 2020

Mudjiman, H. 2007. Belajar Mandiri. Yogyakarta : UNY Press.

Prayitno \& Amti. 1999. Dasar-dasar Bimbingan dan Konseling. Jakarta: Rineka Cipta.

Prayitno. 2012. Jenis Layanan dan Kegiatan Pendukung Konseling (Pendidikan Profesi Konseling). FIP. UNP

Purwoko, B. 2008. Organisasi dan Managemen Bimbingan Konseling. Surabaya: Unesa University Press

Ridwan, B. 2013. Media Pembelajaran. STAIN Salatiga

Sain Hanafy, 2014, Konsep Belajar Dan Pembelajaran, Lentera Pendidikan, Vol.17 No.1 Juni 2014: 66-79

Sutarto, S., Sari, D. P., \& Fathurrochman, I. (2020). Teacher strategies in online learning to increase students' interest in learning during COVID-19 pandemic. Jurnal Konseling dan Pendidikan, 8(3).

Sutrisno, (2020), Meningkatkan Motivasi Belajar Siswa Melalui Layanan Bimbingan Kelompok Dengan Media Video-klip. Vol. 3 No. 1, Februari 2020 Hal. 22-27

Winkel, W. S. 1997. Bimbingan dan Konseling di Institusi Pendidikan. Jakarta: Gramedia Widiasarana 